\title{
Forecasting of strength and durability properties of High Performance Composites by Artificial Neural Networks (ANN)
}

\author{
Magudeaswaran.P ${ }^{1}$, Vivek Kumar $\mathrm{C}^{2}$, MS Britto Jeyakumar ${ }^{3}$ \\ ${ }^{1}$ Professor, Depsrtment of Civil Engineering, Adithya Institute of Technology, Coimbatore, India. \\ ${ }^{2}$ Assistant Professor, Department of Civil Engineering, GRIET, Hyderabad, Telangana, India. \\ ${ }^{3}$ Assistant Professor, Department of Civil Engineering, GRIET, Hyderabad, Telangana, India.
}

\begin{abstract}
High Performance Concrete (HPC) is the high quality concrete that requires special conformity and performance requirements. The objective of this study was to investigate the possibilities of adapting neural expert system like Artificial Neural Network (ANN) in the development of simulator and intelligent system and to predict durability and strength of HPC composites. This soft computing methods emulates the decisionmaking ability of a human expert benefits both the construction industry and the research community. These new methods, if properly utilized, have the potential to increase speed, service life, efficiency, consistency, minimizes errors, saves time and cost which would otherwise be squandered using the conventional approaches.
\end{abstract}

\section{Introduction}

The substantial growth of population has been driven largely by increasing numbers of surviving people results in the development of high-rise buildings and other structures with the accompanying savings costs in congested areas, the requirement for 'High Performance Concrete' is now the present trend. HPC may be a high quality concrete that possesses high workability, high strength, and high durability in comparison to the traditional concrete. These HPC composites contain common ingredients like cement, fine and coarse aggregate with one or more of mineral admixtures materials like ash, silica fume, and M-Sand and frequently chemical admixture like superplasticizer are accustomed improve performance of the concrete. Hence, durability and strength predicting models using the principles of AI are proposed. These prototypes apply neural expert systems as Artificial Neural Network (ANN) and Adaptive Neuro-Fuzzy Inference System (ANFIS) as a tool to predict the sturdiness and strength of concrete. The MATLAB software was accustomed create a neural expert system that employs a high-performance language for technical computing.

\section{Literature Review}

The literature review summarized feasibility studies of neural expert system application for the decision-making ability of a personality's expert in complex concrete performance. The applying of the neural expert system within the concrete field may be a more user-friendly and more precise model. The benefits of ANN and ANFIS could be thanks to the very fact that the creation of the knowledge domain automatically on several nontrivial real-world problems.J. Noorzaei et al (2008)., development of Artificial Neural Networks for forecasting concrete compressive strength. This work focuses on the event of Artificial Neural Networks (ANNs) within the prophecy of compressive strength of concrete after 28 days. To conjecture the compressive strength of concrete six input parameters that are cement, water, silica fume, superplasticizer, fine aggregate, and coarse aggregate are premeditated. The MSE for the training set was $5.33 \%$ for the 400 training data points, $6.13 \%$ for the 100 confirmation data points, and 6.02 of the 139 testing data points. The outcomes obtained from the established computer virus were compared with grades from investigational studies. From the effects obtained artificial neural networks, it can recognize the concrete in terms of 'strength' with a selfreliance level of about $95 \%$, which is taken into account acceptable from an engineering position.

S. Rajasekaran et al (2002)., studied the Forecast of Strength and workability of High Performance of concrete composites using Artificial Neural Network, in which a model supported ANN for predicting the compressive strength and workability for various mixes of High Performance of Concrete from M80 to M150. A formulation for predicting the compressive and workability of HPC is hard due to non-linear connections. During this paper, it's proposed to usage of the ANN during which Back Propagation Architecture is attained. 
Neural Network can foresee the characteristic error of strength $11 \%$ and slump $4 \%$ values of HPC. The grouping quantities for top-grade concrete $80 \mathrm{Mpa}$ and $140 \mathrm{Mpa}$ obtained in these experimentations are given as 1:1.92:2.88 and $1: 1.16: 2.08$.

Seung-Chang Lee et al (2002)., studied the estimate of concrete strength using Artificial Neural Network. The impartial of this paper is to develop the I-PreConS (Intelligent forecast system of Concrete Strength) that deliver in situ strength data of the concrete to simplify concrete form removal and arrangement for construction. For this determination, the system is advanced with Artificial Neural Networks (ANN) which will acquire cylinder test outcomes as training patterns.

ANN doesn't need a specific equation form that fluctuates from traditional forecast models. Relatively than that, it needs sufficient input-output information The initial system features a problem, which it cannot suitably envisage the concrete strength when the curative temperature of a specific curing day is altered. This is frequently because it uses the only architecture, which all nodes are fully associated, and thus it might show too plastic reaction.

As an effort to disentangle this problem, modular ANN is projected, which has multiple architectures selfpossessed of five ANNs (ANN-I V). ANN-I envisages the early strength within one day after placing. From ANN-II to ANN-V forecast the concrete strength at 2nd to 28th day subsequently concrete placing. Concluded a simulation learning, the optimum architectures for individual five ANNs are resolute and therefore the best nodes are examined for inter-connection amongst ANNs.

Two major techniques are applied to extend the accuracy and to predict concrete strength development more precisely. One is to use parameter condensation technique within the determination of input neurons. The opposite is to use the weighting technique of input neurons for more prediction accuracy. This study shows that I-PreConS using ANN is more efficient for predicting the compressive strength development of concrete.

\section{Materials and Methodology}

The ratio of concrete combined proportion was 1:1.91:2.42; in count, 12 no's of concrete mixtures were proportioned where $\mathrm{M}$-sand with ash at the liberal interval $5 \%$ and cement with ash combined with silica fume at a succeeding rate of $2.5 \%$ by mass respectively. The gathering of knowledge involves the standard cement of 53 Grade conformists to IS: 12269-1987, Coarse aggregates conforming to IS383-1970, M sand conformist to grading zone II of IS: 383-1970 was used. The silica fume approving to ASTM C1240 was cast-off for this experimentation and ash (Class F) endorsing to IS 3812-1981. The control mixture was balanced to possess a 28 days strength of 60 $\mathrm{MPa}$ in line with BIS: 10262-1982. The composite of HPC was analyzed and chosen for developing a model. The forecast of the strength and sturdiness properties of HPC had done. The methodology is listed as follows:

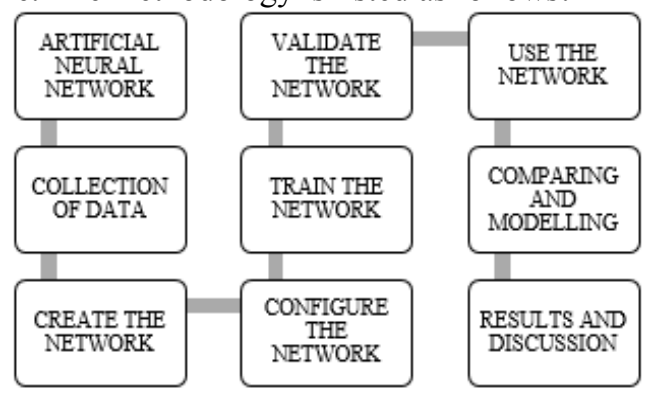

Fig. 1. Artificial Neural Network

\section{A. Collection of data}

The actual values of the compressive strength, split strength, flexural strength, modulus of elasticity, water absorption, acid resistance and RCPT are noticed conventional and for various proportions of silica fume like $2.5 \%, 5 \%, 7.5 \%, 10 \%, 12.5 \%, 15 \%$ and ash like $5 \%, 10 \%$, $15 \%, 20 \%, 25 \%, 30 \%$ by experimental results. These experimental results are trained, tested and validated using Artificial Neural Network.

Table 1. Collection of data

\begin{tabular}{|c|c|c|}
\hline Input data & $\begin{array}{c}\text { Maximum } \\
\text { value }\end{array}$ & Target data \\
\hline Cement & $440 \mathrm{~kg} / \mathrm{m} 3$ & 28-days compressive strength \\
\hline Water & $145 \mathrm{litres}$ & Split tensile strength \\
\hline M-Sand & $839 \mathrm{~kg} / \mathrm{m} 3$ & Flexure strength \\
\hline Silica Fume & $2.5 \%$ & Modulus of elasticity \\
\hline Ages & $\begin{array}{c}1,3,7,14,28, \\
56,90 \text { days }\end{array}$ & Acid resistance test \\
\hline $\begin{array}{c}\text { Super } \\
\text { Plasticizer }\end{array}$ & 9.321 itres & Rapid chloride penetration test \\
\hline $\begin{array}{c}\text { Flyash } \\
\text { Coarse } \\
\text { Aggregate }\end{array}$ & $5 \%$ & Water absorption \\
\hline
\end{tabular}

\section{Artificial Neural Network}

An Artificial Neural Network (ANN) is a computational tool that endeavors to simulate the design and interior features of the human brain and system. It's a random function approximation tool where the intricate relationship amid inputs and outputs are demonstrated. It might be an enormously parallel architecture ended up of diversity of simple, extremely unified method components identified as neurons, this method data by their dynamic state response to external inputs. every input from the input layer is fed up to every node within the hidden layer, and from there to each node on the output layer. in this paper, for the ANN model, seventieth of the complete information were selected for the training step, $15 \%$ for the Validation step, and $15 \%$ for the test step. The entire numbers of datasets are tabulated as follows: 
Table 2. Datasets for ANN

\begin{tabular}{|c|c|c|c|c|}
\hline Datasets & Training & Testing & Validating & Total \\
\hline $\begin{array}{c}\text { Compressive } \\
\text { strength }\end{array}$ & 63.0 & 14.0 & 14.0 & 91 \\
\hline $\begin{array}{c}\text { Split tensile } \\
\text { strength }\end{array}$ & 9.0 & 2.0 & 2.0 & 13 \\
\hline $\begin{array}{c}\text { Flexural } \\
\text { strength }\end{array}$ & 9.0 & 2.0 & 2.0 & 13 \\
\hline $\begin{array}{c}\text { Modulus of } \\
\text { elasticity }\end{array}$ & 9.0 & 2.0 & 2.0 & 13 \\
\hline $\begin{array}{c}\text { Water } \\
\text { absorption }\end{array}$ & 9.0 & 2.0 & 2.0 & 13 \\
\hline Acid resistance & 9.0 & 2.0 & 2.0 & 13 \\
\hline $\begin{array}{c}\text { Rapid chloride } \\
\text { penetration test }\end{array}$ & 9.0 & 2.0 & 2.0 & 13 \\
\hline
\end{tabular}

\section{A. Modeling of HPC using Neural Network}

A neural network is also a robust computational information model that's able to release and signify advanced input output relationships. The stimulus for the occurrence of neural network technology stanched from the will to progress an artificial system that might perform intelligent tasks an equivalent as those performed by the human.

A neural network's data is hold on within interneuron association strengths cited as colligation weights. When the data has been composed, future step in training a network to sort the network entity. The function feed forward net generates a multilayer feedforward network. The subsequent network then be intended with the configure command. Stacking these files produces 2 variables: The input matrix filename|computer file name|name\} inputs and conjointly the massive matrix filename targets. The next step to create the network throughout configuration step the number of neuron among the output layer is about to a minimum. The method of coaching a neural network involves standardization the values of the weights and partialities of the network to enhance network performance, as delineated by the web work recital operate net .performance. The number of neurons in concealed layer is 10 that recommends one concealed layer with 10 neurons.

If the result is not adequate increasing the number of neurons among the hidden layer will increase the power of the network however needs additional computation and to produce over fitting. If no argument is utilized default range of layer. It's used two default range layers and range of neurons in hidden layer as twelve and default coaching operate is trainlm and default transfer operate for hidden layer as tansig and default output layer is purelin.

As a result, completely \{different|completely different $\}$ neural networks proficient on the same drawback will provide diverse outputs for a similar input. To create certain that a network of fantastic accuracy has been found, retrain several times. There are varied different techniques for enlightening upon initial solutions if sophisticated accuracy is anticipated. When the network is accomplished and effective, the network entities are normally used to compute the network response to any input. The system object is utilized to calculate the outputs for a concurrent set of all the input vectors among the info set. \{this is often this can be $\}$ often the batch mode kind of simulation, throughout that all the input vectors square measure placed in one matrix. \{this is typically this can be often much more economical than presenting the vectors one at a time. Neural networks are usually organized with layers.

\section{Results and Discussion}

It is planned to develop an analytical/ mathematical model using ANN and ANFIS approaches for arriving durability and strength. The developed model labeled as a simulation of HPC is that the pc simulating system developed by MATLAB works. In Artificial Neural Network, the numerous parameters of HPC were trained, tested, and valid using a feed-forward neural network. The sse is that the add square error of the system used for training, testing, and verificatory datasets. an adaptive Neuro-Fuzzy reasoning System, the assorted parameters of HPC were trained and valid victimization subtractive using method. The RMSE is that the root mean square error of the system used for using and checking datasets. Among these ANFIS models are superior in terms of the accuracy of their prognostic ability; the results conjointly show ANN-BP to possess a relatively smart level of accuracy.

Table 3. R-value for ANN

\begin{tabular}{|c|c|c|c|}
\hline Parameters & Training & Testing & Validating \\
\hline Compressive strength & 0.99071 & 0.98874 & 0.98937 \\
\hline Split tensile strength & 0.99785 & 0.99976 & 0.99958 \\
\hline Flexural strength & 0.99785 & 0.99976 & 0.99958 \\
\hline Modulus of elasticity & 0.99785 & 0.99976 & 0.99958 \\
\hline Water absorption test & 0.99545 & 0.99703 & 1 \\
\hline Acid resistance test & 0.99545 & 0.99703 & 1 \\
\hline $\begin{array}{c}\text { Rapid Chloride } \\
\text { Penetration Test }\end{array}$ & 0.99545 & 0.99703 & 1 \\
\hline
\end{tabular}

\section{References}

1. R. Agarwal., et.al., Effect of fibre reinforcing index on compressive and bond strength of steel fibre reinforced concrete, Journal of the institutions of engineers (India), Vol. 77, pp. 37-40, (1996).

2. MarekSłon'ski, "A comparison of model selection methods for compressive strength prediction of highperformance concrete using neural networks", Computers and Structures, Vol 88, Issue2010, pp 1248-1253.

3. Tao Ji, et.al. "A concrete mix proportion design algorithm based on artificial neural networks" Issue 13 January 2006. 
4. Osama Hodhod, et.al "Analysis of sulfate resistance in concrete based on Artificial Neural Networks and USBR4908-modeling” Issue 27 March 2013.

5. Vijay Pal Singh, et.al "Prediction of compressive strength using artificial neural network" International Journal of Civil, Environmental, Structural, Construction and Architectural Engineering, Vol:7, No:12, Issue 2013.

6. Hamid Eskandari, et.al, "Effect of 32.5 and 42.5 cement grades on ANN prediction of fibrocement compressive strength" International Conference on Industrial Engineering, ICIE Issue2016.

7. Neela Deshpande, et.al, "Modeling compressive strength of recycled aggregate concrete by artificial neural network, model tree and non-linear regression" International Journal of Sustainable Built Environment, Issue 4 December 2014.

8. Faezehossadat Khademi,Sayed et.al "Predicting strength of recycled aggregate concrete using artificial neural network, adaptive neuro-fuzzy inference system and multiple linear regression" International Journal of Sustainable Built Environment, Issue 17 September 2016.

9. Ahmet $\mathrm{O}$ ztas, et.al "Predicting the compressive strength and slump of high strength concrete using neural network" Construction and Building Materials, Vol 20 (2006) 769-775, Issue 23 March 2005.

10. O.A. Hodhoda et.al G. Salama, Ain "Simulation of expansion in cement based materials subjected to external sulfate attack" Shams Engineering Journal, Issue 1 July 2013.

11. O.A. Hodhoda, et.al, "Developing an artificial neural network model to evaluate chloride diffusivity in high performance concrete" Housing and Building National Research Center, Issue 10 September 2012.

12. Tummala Suresh Kumar, Kosaraju Satyanarayana, Materials Today: Proceeding, 26 (2), 3228-3233, (2020).

13. Anoop K. Sooda, et.al "Experimental investigation and empirical modelling of FDM process for compressive strength improvement" Journal of Advanced Research, Issue June 2012, pp 81-90.

14. M. Aminul Haque, et.al, "Non-linear models for the prediction of specified design strengths of concretes development profile" Housing and Building National Research Center, Issue 18 April 2016.

15. Salah A. Abo-El-Enein, et.al "Physico-mechanical properties of high performance concrete using different aggregates in presence of silica fume" Housing and Building National Research Center, Issue 18 June 2013. 